\title{
PORTAL HYPERTENSIVE BILIOPATHY
}

Preeti Singh Dhoat ${ }^{1}$, Ashok Khurana², Jivesh Mittal ${ }^{3}$, Amandeep Kaur Sandhu ${ }^{4}$

\section{HOW TO CITE THIS ARTICLE:}

Preeti Singh Dhoat, Ashok Khurana, Jivesh Mittal, Amandeep Kaur Sandhu. "Portal Hypertensive Biliopathy". Journal of Evolution of Medical and Dental Sciences 2014; Vol. 3, Issue 69, December 11; Page: 14874-14876, DOI: $10.14260 /$ jemds/2014/3999

ABSTRACT: Portal biliopathy (PB) is defined as biliary obstruction associated with enlarged collaterals in the setting of chronic extrahepatic portal vein occlusion (portal vein thrombosis EHPVO) or cavernous transformation of the portal vein. Although patients with portal biliopathy normally have asymptomatic biliary dilatation or an increase in liver enzyme levels, they may rarely experience jaundice, cholangitis or choledocholithiasis. The present case is of 17 year old male presenting with obstructive jaundice, malena, cholelithiasis secondary to portal venous thrombosis and cavernous transformation of portal vein due to CBD stricture secondary to Portal Hypertensive Biliopathy (PHB).

KEYWORDS: Portal Biliopathy, EHPVO

INTRODUCTION: Portal biliopathy can be defined as biliary ductal and gall bladder wall abnormalities secondary to portal hypertension (PH) more commonly due to portal vein thrombosis. ${ }^{1,2}$ In $30 \%$ cases of portal biliopathy, extrahepatic portal hypertension is the predisposing cofactor. In as many as half of patients, there is no preceding cause. ${ }^{3}$ Symptomatic biliary obstruction due to cavernous transformation of portal vein was first reported in 1944 by Fraser and Brown. ${ }^{4}$

CASE REPORT: A 17 year old male presented with obstructive jaundice for 1 year, malena for 2 months, ascites for 2 months, and pedal edema for 2 months. He had no history of smoking or alcohol consumption.

At time of admission, patient's sensorium was normal and vitals were stable. Patient was deeply icteric. There was moderate splenomegaly. Gall bladder was not palpable. Moderate ascites was present.

Laboratory studies showed $\mathrm{Hb} 8.2$ g\% with dimorphic smear. TLC- 4700/mm, ${ }^{3}$ DLCneutrophils $70 \%$, lymphocytes $25 \%$, monocytes $2 \%$ eosinophil $3 \%$. Total bilirubin was $16 \mathrm{mg} / \mathrm{dl}$ with direct fraction $5.7 \mathrm{mg} / \mathrm{dl}$ indirect $10.3 \mathrm{mg} / \mathrm{dl}$, Alkaline phosphatase $494 \mathrm{U} / \mathrm{L}$, AST/SGOT $129 \mathrm{U} / \mathrm{L}$, ALT/SGPT 38 U/L. FBS 89 mg/dl. HCV was weakly positive.

Ascitic fluid showed tubercular picture. Proteins were $4.4 \mathrm{gm} / \mathrm{dl}, 100$ cells/mm3 were seen which were mainly lymphocytes and reactive mesothelial cells. Coagulation profile was done and INR was 1.7. UGI Endoscopy showed Grade III oesophageal varices and gastropathy. USG whole abdomen showed dilated IHBR's with splenomegaly with massive ascites. CECT abdomen showed liver size of $17.85 \mathrm{cms}$ with intrahepatic biliary radicles markedly dilated. CBD was narrowed and showed thickening of its wall due to stricture of CBD caused by compression of CBD lumen by enlarged collaterals and due to pericholedochal fibrosis. Spleen measured $22.5 \mathrm{cms}$, portal vein $14 \mathrm{~mm}$, splenic vein $10 \mathrm{~mm}$. Multiple collaterals were seen at splenic hilum, splenorenal space, along the course of splenic vein. Right and left tributaries of the portal vein were not visualised due to thrombosis and cavernous formation at porta hepatis. Moderate ascites seen with thickened folds of gut loop. MRCP 


\section{CASE REPORT}

showed dilated IHBR, dilated CBD with tapering and narrowing proximal to ampulla, hypodense calculus measuring $7 \mathrm{~mm}$ in neck of GB, dilated cystic duct, portal vein compressed by CBD and moderate free fluid seen in peritoneal cavity.

TREATMENT: Initially patient was treated conservatively with i/v fluids and antibiotics. ATT was started and patient showed marked improvement. Dilatation and stenting of CBD stricture was done and patient reffered to higher Centre for further treatment.

DISCUSSION: EHPVO is a common cause of PH in the developing countries in $40 \%$ of all patients with PH. 5 ,6 Only $11 \%$ of PB patients have cirrhosis while $95 \%$ have extension of portal vein thrombosis. A minimal increase in total bilirubin and alkaline phosphatase levels occurs in $40 \%-80 \%$ of patients. ${ }^{7}$ EHPVO is a common cause of major UGI bleeding among children.8,9 In adults, EHPVO is often recognised when evaluating for other disorders or with uncommon presentation such as jaundice, ascites or pruritis resulting from prolonged portal hypertension. ${ }^{10}$ The portal vein is transformed into a cavernoma, which is a bunch of multiple collateral veins around the obstructed portion of portal vein. Omphalitis and intraabdominal sepsis are common causes in neonates and children. Adults develop EHPVO due to increased blood coagulobility, local inflammation, intraabdominal sepsis, myeloproliferative disorders, underlying cirrhosis or tumour of liver, bile duct or pancreas. ${ }^{11,12,13}$ In the present case the investigations showed no other cause except for abdominal tuberculosis. Endoscopic treatment of varices is capable of taking care of acute variceal bleeding. ${ }^{6}$ Various shunt surgery are indicated in massive splenomegaly, hypersplenism, ectopic varices, gastropathy, enteropathy.8,9 Porto systemic shunt is indicated to decompress the portal system. If changes of PB do not regress hepaticojejunostomy can be performed to relieve obstruction. ${ }^{14}$ It is believed that external pressure of portal cavernoma or collaterals and/or ischemia is the causative factor for biliary stricture.7,11 ERCP or MRI angiography can pick up PB even before onset of jaundice, pain or raised liver enzymes. ${ }^{11}$ The differential diagnosis includes biliary ascariasis and primary sclerosing cholangitis. Only few cases reported earlier had unusual presentations. Sumathi et.al presented a case of PH with obstructive jaundice. ${ }^{15}$ Chawla et al reported a case of PB with obstructive jaundice and haemetemesis. ${ }^{3}$ Proper case management is very important as prolonged biliary obstruction can lead to development of ascending cholangitis and later on secondary biliary cirrhosis. ${ }^{2}$ Biliary portal hypertension is a rare presentation and is of concern not only to the physicians but an exercise for the radiologist and surgeons as far as diagnosis on strong suspicion of the condition and treatment is concerned. Early diagnosis can prevent mortality and morbidity.

\section{REFERENCES:}

1. Azize Ashraf B, Sophie Z. Noncirrhotic portal hypertension in young adult. Coll physicians surg pal 2002; 10: 566-7.

2. Chandra R, Kapoor D, Thamhan A, Chaudhary A, Sam SK. Portal biliopathy review. J Gasteroenteral Hepatol 2001; 16: 1086-92.

3. Chawla A, Maheshwari ML, Parman H. Obstructive jaundice in a case of portal hypertension. $\mathrm{Br} \mathrm{j}$ Radio 2003; 7: 667-9.

4. Fraser j, Brown AK. A clinical syndrome associated with a rare anomaly of the vena portal system. Surg gynecol obstet 1944; 78: 520-524. 


\section{CASE REPORT}

5. Poddar U, Thapa BR, Rao KL, Singh K. Etiological spectrum of esophageal varices due to portal hypertension in Indian children. Is it different from the rest? J Gastroenterol Hepatol 2008; 23: 1354-7 (pub med).

6. Stringer MD, Howard ER. Long term outcome after injection sclerotherapy for esophageal varices in children with extrahepatic portal hypertension. Gut 1994; 35: 257-9(PMC free article) (pub med).

7. Khuroo MS, Yatoo GN, Zargal S. Biliary abnormalities associated with extrahepatic portal vein obstruction. Hepatology 1998; 17: 807-13.

8. Mitra SK, Rao KL, Narsimhan KL, Dilawari JB, Batra YK, Chawla Y, et al. side to side splenorenal shunt without splenectomy in noncirrhotic portal hypertension in children. J Pediatr surg 1993: 28, 398-402.(pub med)

9. Rao KL, Goyal A, Menon P, Thapa BR, Narsimhan KL, Chaudhary SK, et al. Extrahepatic portal hypertension in children. Observations on three surgical procedures. Pediatr Surg Int.2004; 20; 679-84.

10. Menon P, Rao KL, Bhattacharya A, Thapa BR, Chaudhary SK, Mahajan JK et al. Extrahepatic portal hypertension- Quality of life and somatic growth after surgery. E ur j pediatr surg 2005; 15: 827. (pub med)

11. Dilawari JB, Chawla YK. Pseudosclerosing cholangitis in extrahepatic portal venous obstruction Gut 1992; 33: 272-6. (pmc free article)(pub med).

12. Sarin SK, Bhatia V, Makwane U. Portal biliopathy in extrahepatic portal vein obstruction.Indian J Gastroenterol 1992; 2: 82.

13. Dhiman RK, Puri P, Chawla Y, Minz M, Bapuraj JR, Gupta S et al. Biliary changes in extrahepatic portal vein obstruction: Compression by collaterals or ischemia? Gastrointest Endosc 1999; 50: 646-52.

14. Muhmmad Shabba Alam, Qazi Saadbin Khalid, Muhammad Zeesha, Zishan Haider.Portal biliopathy. J Pak Med Assoc 2012; 62: 177-80.

15. B Sumathi, J Randhir, KS Shahhar, S Malathi, D N Reddy, V Jayanthi. Portal biloiopathy JAPI. 2006; 54: 483.

\section{AUTHORS:}

1. Preeti Singh Dhoat

2. Ashok Khurana

3. Jivesh Mittal

4. Amandeep Kaur Sandhu

\section{PARTICULARS OF CONTRIBUTORS:}

1. Assistant Professor, Department of Medicine, SGRDIMSR, Amritsar.

2. Professor, Department of Medicine, SGRDIMSR, Amritsar.

3. Senior Resident, Department of Medicine, MMMCH, Kumarhatti, Solan.
4. Post Graduate, Department of Medicine, SGRDIMSR, Amritsar.

\section{NAME ADDRESS EMAIL ID OF THE CORRESPONDING AUTHOR:}

Dr. Jivesh Mittal, \# 21892, Near Shiv Mandir, 100 Feet Road, Bathinda.

Email: embracelove34@gmail.com

Date of Submission: 26/11/2014.

Date of Peer Review: 27/11/2014.

Date of Acceptance: 05/12/2014.

Date of Publishing: 11/12/2014. 